\title{
Qualidade da composição do extrato de própolis verde sob influência do Bioma Caatinga
}

\section{Maria Verônica Lins ${ }^{1}$, Marcos Barros de Medeiros ${ }^{1}$, Osvaldo Soares da Silva ${ }^{2}$, Rosilene Agra da Silva ${ }^{2}$, Patrício Borges Maracajá ${ }^{2}$, Lígia Maria Ribeiro Lima ${ }^{3}$, Virgínia Maria Magliano Morais ${ }^{4}$ e Hélder Formiga Fernandes ${ }^{5}$}

\begin{abstract}
${ }^{1}$ Universidade Federal da Paraíba. Centro de Ciências Humanas Sociais e Agrárias. Departamento de Agricultura. Campus IV. Bananeiras-PB, Brasil (CEP 58220-000). E-mail: agrolins@yahoo.com.br.

${ }^{2}$ Universidade Federal de Campina Grande. Centro de Ciências e Tecnologia Agroalimentar. Rua Jairo Vieira Feitosa, 1770. Pereiros. Pombal-PB, Brasil (CEP 58840-000).

${ }^{3}$ Universidade Estadual da Paraíba. Departamento de Engenharia Sanitária e Ambiental. Rua Juvêncio Arruda, S/№. Bodocongó. Campina Grande-PB, Brasil (58109-970).

${ }^{4}$ Universidade Federal da Paraíba. Centro de Educação. Departamento de Fundamentação da Educação. Campus I. João Pessoa-PB, Brasil (CEP 58051-900).

5Universidade Federal da Paraíba. Centro de Ciências Exatas e da Natureza. Programa de Pós-Graduação em Desenvolvimento e Meio Ambiente. Campus I. João Pessoa-PB, Brasil (CEP 58051-900).
\end{abstract}

Resumo. A própolis é um produto apícola de constituição química complexa produzida pelas abelhas. Elas colhem as gotas e partículas expiradas dos brotos e botões florais que se unem a

Recebido

$23 / 12 / 2019$ outras substâncias e secreções, e transformam-se em uma rica resina com várias finalidades de uso. 0 objetivo geral desta pesquisa foi avaliar a influência do armazenamento a frio da própolis verde colhida na Região Curimataú Oriental, no semiárido brasileiro do Estado da Paraíba, sob temperatura controlada. Foram analisadas 20 amostras de própolis; divididas em dois grupos A e B com 10 amostras cada um. As amostras foram submetidas ao armazenamento a frio a $10^{\circ} \mathrm{C}$, por um período de 12 meses; as amostras do grupo $\mathrm{B}$ foram colhidas e imediatamente submetidas às análises, em temperatura ambiente. Foi possível concluir que as características físicas e químicas para os extratos das própolis, verde, permaneceu com suas características preservadas mantendo excelente qualidade em função do armazenamento, por um período de 12 meses, conclui-se que a própolis verde da Região do Curimataú Paraibano tem uma qualidade excepcional.

Palavras-chave: Qualidade; Semiárido; Caatinga; Apicultura.
Aceito

$28 / 07 / 2020$

Disponível on line

$09 / 08 / 2020$

Publicado

$31 / 08 / 2020$

Acesso aberto

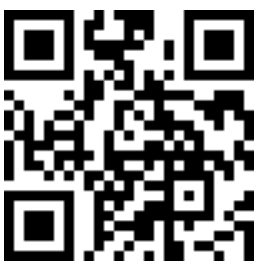

ISSN 2359-1412/RBGAS-2019-0116/2020/7/16/19/727

Rev. Bras. Gest. Amb. Sustent.

http://revista.ecogestaobrasil.net 


\begin{abstract}
Quality of the composition of green propolis extract under the influence of the Caatinga Biome. Propolis is a bee product of complex chemical composition produced by bees. They collect the droplets and expired particles from the buds and flower sprouts that unite with other substances and secretions, and become a rich resin for various purposes. The general objective of this research was to evaluate the influence of cold storage of green propolis harvested in the Eastern Curimataú Region, in the Brazilian semiarid State of Paraíba, under controlled temperature. Twenty propolis samples were analyzed; divided into two groups A and B with 10 samples each. The samples were subjected to cold storage at $10^{\circ} \mathrm{C}$, for a period of 12 months. Group B samples were collected and immediately subjected to analysis at room temperature. It was possible to conclude that the physical-chemical characteristics for the extracts of propolis, green, remained with their characteristics preserved maintaining excellent quality due to the storage, for a period of 12 months, it is concluded that the green propolis from the Region of Curimataú Paraibano has exceptional quality.
\end{abstract}

Keywords: Quality; Semiarid; Caatinga; Beekeeping.

\author{
() 0000-0003-1411-9259 \\ Maria Verônica Lins \\ (D) 0000-0002-1633-3227 \\ Marcos Barros de \\ Medeiros \\ (D) 0000-0002-2029-9279 \\ Osvaldo Soares da \\ Silva \\ (ㄱ) 0000-0001-9232-7403 \\ Rosilene Agra da Silva \\ (ㄱ) 0000-0003-4812-0389 \\ Patrício Borges \\ Maracajá \\ (D) 0000-0002-3334-2635 \\ Lígia Maria Ribeiro \\ Lima \\ D) 0000-0001-8083-1979 \\ Virgínia Maria \\ Magliano Morais \\ (1) 0000-0002-0370-0673 \\ Hélder Formiga \\ Fernandes
}

\section{Introdução}

A própolis do Brasil foi classificada em 12 tipos diferentes, segundo seu perfil químico obtido pelas técnicas de espectrofotometria de absorção na região UV - Visível, Cromatografia de Camada Delgada Analítica (CCDA) e Cromatografia Líquida de Alta Eficiência (CLA), além da avaliação das atividades antimicrobiana e antioxidante (Alencar et al., 2005).

Estudos mais recentes afirmam que própolis se refere a um produto apícola resinoso, formado por substâncias coletadas de plantas produzidas por abelhas. Nem todas as espécies de abelhas produzem própolis da mesma forma, colônias de Apis dorsata Fabricius, 1793, por exemplo, utiliza própolis para reforçar a colmeia, já Apis cerana Fabricius, 1793, não a utiliza para nenhuma finalidade, sendo Apis mellifera L., a que mais usa a própolis para as mais diversas funções dentro da colmeia. Quando comparada a outros produtos de origem medicinal, a composição da própolis é muito mais variável, de tal modo que as amostras de uma mesma localidade possuem composições totalmente distintas. A própolis apresenta em proporções variáveis, resinas, cera das abelhas, substâncias voláteis, pólen e outros constituintes minoritários como minerais e vitaminas (Więckiewicz et al., 2013).

Certos componentes químicos da própolis têm origem botânica cujo pólen não foi totalmente incorporado à amostra, ou mesmo outros fatores das próprias abelhas, influenciando no perfil químico (Teixeira et al., 2003).

Parte dos seus constituintes também se origina de fonte animal como a cera de abelha e outros obtidos de plantas como resinas, mucilagem, goma, látex, fragmento de folhas e gemas foliares, a atividade biológica da própolis é atribuída a esta substância derivada de plantas. Os diversos aspectos químicos da própolis que têm ações eficientes e 
importantes para humanidade, entre eles os flavonoides e os ácidos fenólicos que apresentam atividade antioxidante, antifúngica, antibacteriana, são relevantes componentes químicos aplicados nas mais variadas áreas do conhecimento, ainda pouco estudado. De certa forma, o papel das abelhas em colher todo esse material, unir, misturar, transportar até a colmeia configura um novo produto como a própolis é de fato (Salatino et al., 2015).

Diante do exposto, foi desenvolvida uma investigação acerca da avaliação da influência do armazenamento das própolis a frio frente às analisadas em temperatura ambiente, colhidas na mesorregião do agreste paraibano, com o objetivo de utilizá-lo para fins de composição com outros extratos de origem vegetal.

Avaliar a influência do armazenamento a frio da própolis verde sob temperatura controlada de $10{ }^{\circ} \mathrm{C}$, durante 12 meses.

\section{Metodologia}

Para essa pesquisa foi utilizada própolis verde produzida por abelhas (Apis mellifera L.) colhida na Região do Curimataú Oriental.

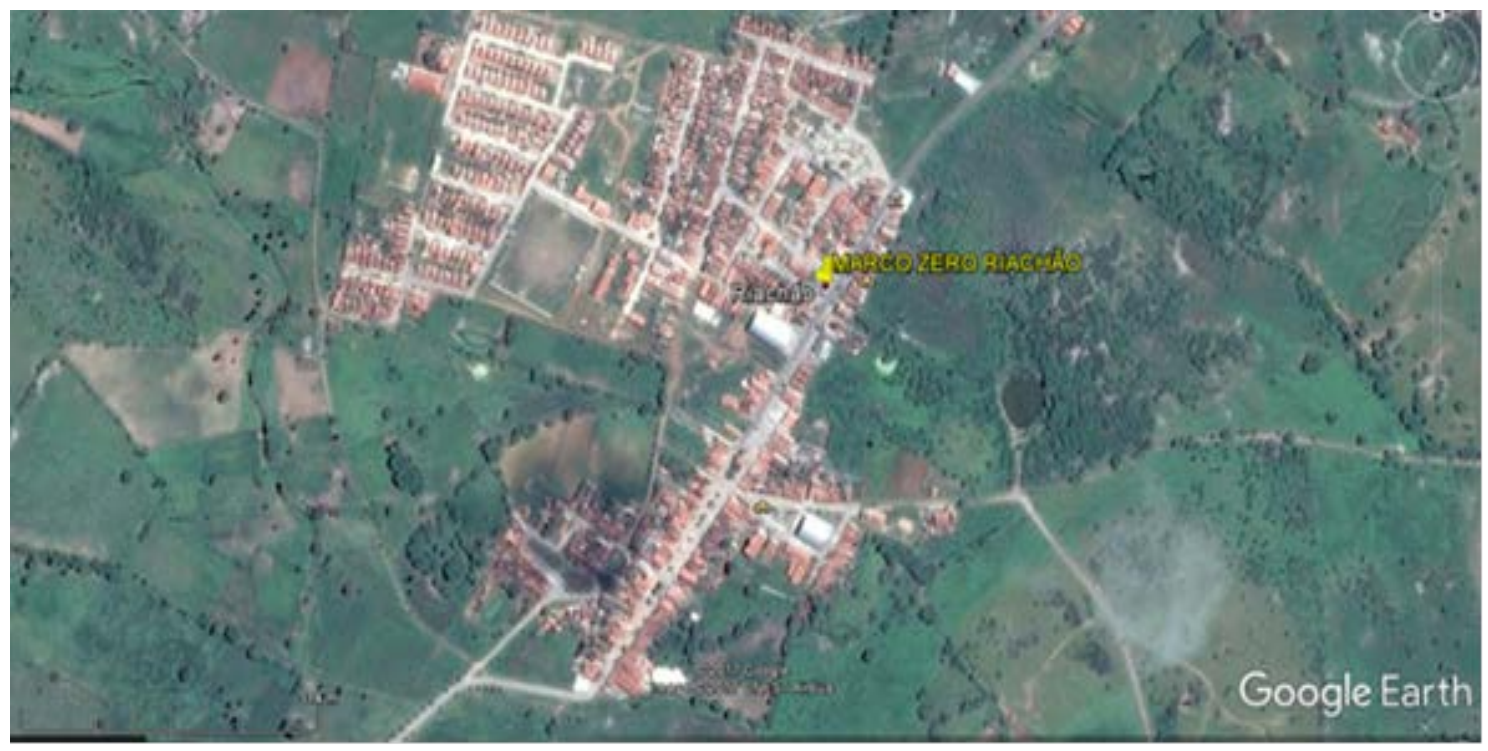

Figura 1. Localização em coordenadas da Região do Curimataú Oriental Paraibano. Fonte: Google Earth (2019).

Na Figura 1 está representado o mapa com as coordenadas do marco zero do Curimataú Oriental Paraibano (latitude 6 $6^{\circ} 32^{\prime} 27,78^{\prime \prime}$ S e longitude $35^{\circ} 39^{\prime} 34,93^{\prime \prime}$ ). Para captação das imagens foi utilizado um aplicativo GPS Data, enviadas para Google Earth.

\section{Registro das principais espécies nas regiões estudadas}

Foi realizado um levantamento florístico para o registro dos indivíduos em torno dos apiários no Curimataú Oriental, isolou-se a área em $1 \mathrm{~km}$ para norte, sul, leste e oeste. Em seguida foi aplicado o método de parcelamento aleatório sendo cada parcela com dimensão de 10 m x 20 m totalizando 16 parcelas. Conforme ilustrado na Figura 2. 


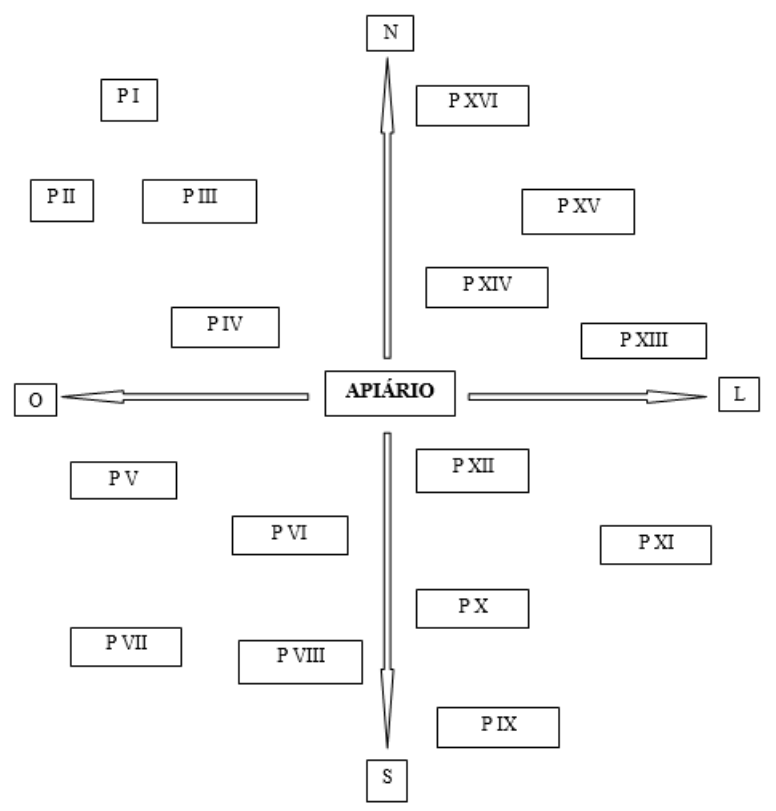

Figura 2. Levantamento florístico utilizando o método de parcelamento aleatório. Legenda: P Parcela.

Em seguida foi realizada a marcação dos indivíduos com etiquetas plásticas devidamente enumeradas em ordem crescente. Após a contagem dos números de indivíduos foram aplicadas as equações para o cálculo dos parâmetros a densidade total, a densidade relativa e frequência relativa, usando as seguintes fórmulas (Rodal et al., 2013):

\author{
Densidade Total (DT)/DT $=(\mathrm{N} . \mathrm{U}) / \mathrm{A}$ \\ Densidade Relativa (Drt) $/$ Drt $=(\mathrm{Nt} / \mathrm{N}) \times 100$ \\ Frequência (Frt) $/$ Fat $=($ nAt $/$ NAT $) \times 100$
}

Foram utilizadas 20 amostras de própolis produzidas por abelhas (Apis mellifera L.), colhidas na Região do Curimataú Oriental da Paraíba. As amostras foram divididas em dois grupos A e B:

Grupo A - Foram 10 amostras de própolis verde armazenada a $10{ }^{\circ} \mathrm{C}$ em BDO por um período de 12 meses.

Grupo B - Foram 10 amostras de própolis verde armazenada em condição ambiente com média de entre $30^{\circ} \mathrm{C}$ a $38^{\circ} \mathrm{C}$.

\title{
Amostras de própolis verde
}

Foram colhidas 20 amostras de própolis verde, na Microrregião Curimataú Oriental, pertencente à Mesorregião do Agreste Paraibano, no Município de Riachão, Assentamento Baixio, a partir da $16: 00 \mathrm{~h}$, com temperatura média de $32{ }^{\circ} \mathrm{C}$. As amostras foram doadas pela Associação dos Apicultores do Riachão. 0 apiário está localizado nas seguintes coordenadas geográficas $6^{\circ} 33^{\prime} 41,62^{\prime \prime}$ latitude $S$ e $35^{\circ} 40^{\prime} 45,54^{\prime \prime}$ longitude 0 . Após a realização da coleta das própolis, as amostras foram devidamente acondicionadas em recipientes de vidro, com capacidade para $50 \mathrm{~g}$, que apresentou peso médio de $12 \mathrm{~g}$. 


\section{Análises físicas e químicas da própolis}

As análises físicas e químicas foram realizadas de acordo com metodologia recomendada pelo dispositivo legal no Brasil para indicar a qualidade da própolis, foram preconizadas pela AOAC (1995).

Umidade $/ \%)$ Umidade $=\left[\left(\frac{P C+P A-P F}{P A}\right)\right] \times 100(\%)$ Umidade $=\left[\left(\frac{P C+P A-P F}{P A}\right)\right] \times 100$
Teor de cera $/ \%$ Cera $=\left[\left(\frac{P_{4-} P_{8}}{P_{1}}\right)\right] \times 100 \%$ Cera $=\left[\left(\frac{P_{4-} P_{8}}{P_{1}}\right)\right] \times 100$
Teor de cinzas $/(\%) C r=\left[\left(\frac{W_{3}-W_{1}}{W_{2}-W_{1}}\right)\right] \times 100(\%) C r=\left[\left(\frac{W_{3}-W_{1}}{W_{2}-W_{1}}\right)\right] \times 100$

As leituras de medição do pH foram realizadas em pHgâmetro.

\section{Processos de preparação para extratos de própolis etanólico e aquoso}

No processo de preparação para os extratos etanólicos das própolis foram utilizados $20 \%$ das amostras das própolis in natura $(100 \mathrm{~mL})$ e $80 \%$ do álcool cereal, na proporção matemática de $20 \%$ do soluto/80\% de solvente. Misturada e triturada em um liquidificador convencional, a mistura foi mantida em agitação periódica de $12 \mathrm{~h}$ por 7 dias, em temperatura ambiente. Em seguida foi centrifugada (calibragem de 8,800 g e força G igual a 7,690 g), com temperatura de $20{ }^{\circ} \mathrm{C}$ por $20 \mathrm{~min}$. Também foi realizada a filtragem do sobrenadante em papel de filtro e em seguida posto para refrigerar a $4{ }^{\circ} \mathrm{C}$. Após o descanso de $3 \mathrm{~h}$, o material foi submetido à nova filtragem e levado para armazenamento sob condições ambiente de temperatura e luz.

\section{Resultados e discussão}

\section{Registro das principais espécies botânicas nas regiões estudadas}

Com base nas espécies identificadas (Tabela 1) foi possível observar que na distância de 200 m e 400 m ocorre a mesma frequência de vegetação que em $1.000 \mathrm{~m}$, as repetições das 23 espécies em proporções semelhantes e na forma como estão dispostas na natureza configura ainda que há uma característica similar da composição da vegetação regional com Densidade absoluta (DAI) de 5.215 indivíduos/ha, e que as plantas oferecem às abelhas o pólen, néctar e resina, entre outras substâncias que compõe a própolis.

As plantas identificadas, com princípios medicinais são utilizadas pela comunidade local, algumas já com comprovação científica. Observa-se ainda que a um grande número de espécies diferentes, misturadas em uma mesma área, ocorrendo uma interação mútua com uma diversidade complexa, cada espécie apresenta seu comportamento e suas particularidades.

A exemplo da aroeira que em trabalhos já realizados foi encontrado um alto teor de fenóis, em média 302,72 mg para $100 \mathrm{~g}$ do extrato, com o passar dos anos estudos mostraram evidências que o consumo de compostos fenólicos traz benefícios ao organismo, este fato está diretamente relacionado ao seu poder antioxidante presente na planta (Degáspari et al., 2004; Paula et al., 2016). 
Tabela 1. Principais espécies que compõe a flora apícola em torno do apiário do Curimataú Oriental.

\begin{tabular}{|c|c|c|c|c|c|c|}
\hline $\begin{array}{l}\text { Nome } \\
\text { Popular }\end{array}$ & Nome científico & Família & Floração & $\begin{array}{l}\text { № de } \\
\text { Táxon }\end{array}$ & Drt (\%) & Frt (\%) \\
\hline Marmeleiro & $\begin{array}{c}\text { Croton } \\
\text { sonderianus }\end{array}$ & Rosaceae & $\mathrm{fev} / \mathrm{mar}$ & 430 & 25,7639 & 10,4297 \\
\hline $\begin{array}{l}\text { Jurema } \\
\text { branca }\end{array}$ & $\begin{array}{c}\text { Piptadenia } \\
\text { stipulacea }\end{array}$ & Fabaceae & mar/jun & 259 & 15,5182 & 5,2148 \\
\hline Maniçoba & $\begin{array}{c}\text { Manihot } \\
\text { pseudoglaziovii }\end{array}$ & Euphorbiaceae & set/out & 252 & 15,0988 & 4,1718 \\
\hline $\begin{array}{c}\text { Jurema } \\
\text { Preta } \\
\end{array}$ & $\begin{array}{c}\text { Mimosa } \\
\text { tenuiflora }\end{array}$ & Fabaceae & set/jan & 190 & 11,3840 & 4,1718 \\
\hline Catingueira & $\begin{array}{l}\text { Caesalpinia } \\
\text { pyramidalis }\end{array}$ & Caesalpinioideae & $\mathrm{fev} / \mathrm{mar}$ & 143 & 8,5680 & 8,3437 \\
\hline Mororó & $\begin{array}{c}\text { Bauhinia } \\
\text { aromatica }\end{array}$ & Fabaceae & set/nov & 101 & 6,0515 & 7,3007 \\
\hline Angico & $\begin{array}{c}\text { Anadenanthera } \\
\text { colubrina }\end{array}$ & Mimosoideae & dez & 80 & 4,7932 & 7,1756 \\
\hline Aroeira & $\begin{array}{c}\text { Schinus } \\
\text { terebinthifolius }\end{array}$ & Anacardiaceae & fev/abr & 56 & 3,3553 & 8,3437 \\
\hline Cajueiro & $\begin{array}{c}\text { Anacardium } \\
\text { occidentale }\end{array}$ & Anacardiaceae & ago/nov & 26 & 1,5578 & 5,2148 \\
\hline $\begin{array}{l}\text { Pinhão } \\
\text { manso }\end{array}$ & Jatropha curcas & Euphorbiaceae & $\mathrm{mar} / \mathrm{abr}$ & 25 & 1,4979 & 4,1718 \\
\hline Jucazeiro & $\begin{array}{c}\text { Caesalpinia } \\
\text { ferrea }\end{array}$ & Fabaceae & out & 20 & 1,1983 & 6,2578 \\
\hline Juazeiro & Ziziphus juazeiro & Rhamnaceae & out & 19 & 1,1384 & 3,1289 \\
\hline Feijão bravo & $\begin{array}{c}\text { Capparis flexuosa } \\
\text { L. } \\
\end{array}$ & Cyperaceae & set & 12 & 0,7189 & - \\
\hline Umbuzeiro & $\begin{array}{c}\text { Spondias } \\
\text { tuberosa } \\
\end{array}$ & Anacardiáceas & jan & 11 & 0,6590 & 4,1718 \\
\hline Leucena & $\begin{array}{c}\text { Leucaena } \\
\text { leucocephala }\end{array}$ & Mimosaceae & jan/out & 10 & 0,5991 & 1,0429 \\
\hline Ipê roxo & $\begin{array}{c}\text { Tabebuia } \\
\text { avellanedae }\end{array}$ & Bignoniaceae & ago & 9 & 0,5392 & 5,2148 \\
\hline Velame & $\begin{array}{l}\text { Cardiospermum } \\
\text { halicacabum L. }\end{array}$ & Sapindaceae & jan/dez & 5 & 0,2995 & 2,0859 \\
\hline Pereiro & $\begin{array}{c}\text { Aspidosperma } \\
\text { pyrifolium }\end{array}$ & Fabaceae & fev & 5 & 0,2995 & 2,0859 \\
\hline Mangueira & Mangifera indica & Anacardiaceae & dez & 5 & 0,2995 & 1,0429 \\
\hline Umbu cajá & - & - & - & 4 & 0,2396 & 4,1718 \\
\hline Faveleira & $\begin{array}{c}\text { Cnidoscolus } \\
\text { phyllacanthus }\end{array}$ & Euphorbiaceae & set/out & 3 & 0,1797 & 1,0429 \\
\hline Sucupira & $\begin{array}{c}\text { Bowdichia } \\
\text { virgilioides }\end{array}$ & Fabaceae & ago & 2 & 0,1198 & 1,0429 \\
\hline Mata fome & $\begin{array}{c}\text { Pithecellobium } \\
\text { dulce }\end{array}$ & Fabaceae & Set/out & 2 & 0,1198 & 1,0429 \\
\hline 23 & 23 & 10 & - & 1.669 & 99,9989 & 99,9987 \\
\hline
\end{tabular}

Legenda: Drt - Densidade relativa; Frt - Frequência relativa.

Foram 23 espécies identificadas no raio de $1 \mathrm{~km}$, com uma densidade total de 1.669 indivíduos/ha em 16 parcelas, centenas delas repetidas, que contribuíram para alta 
complexidade da composição da própolis verde nesta região, podendo-se afirmar que o teor de fenóis nas plantas está diretamente relacionado ao índice de fenóis encontrado na composição da própolis. Destacamos ainda a interação das abelhas com a perpetuação destas espécies na região, que lhe permitem tirar da polinização a manutenção do ecossistema. 0 apiário do Município do Riachão está localizado em uma área da associação dos apicultores, com 80 colmeias, fica em uma reserva legal com aproximadamente 6 ha.

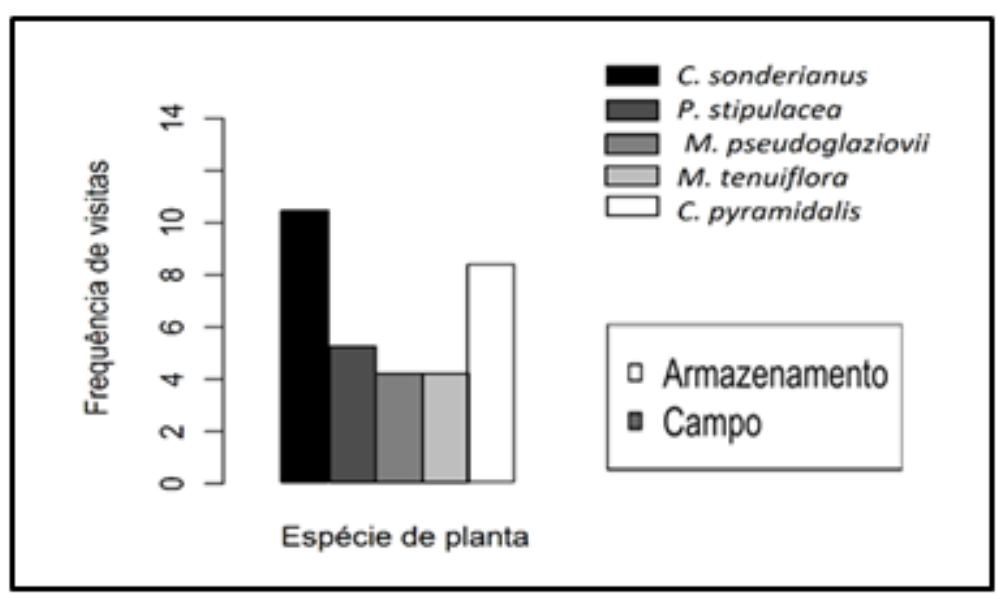

Figura 3. Valores das em cinco espécies mais frequentes na área de estudo do Curimataú Oriental Paraibano.

As cinco plantas mais frequentes registradas nas 16 parcelas do Curimataú Oriental Paraibano preferencialmente visitadas por abelhas Apis mellifera L. foram marmeleiro, jurema branca, maniçoba, jurema preta e catingueira.

Os valores médios encontrados, por meio desse estudo, versam sobre a qualidade de extratos de própolis verde, em função da Região, Curimataú Oriental do Estado da Paraíba.

\section{Umidade}

Na Figura 4 estão ilustrados os resultados obtidos para as análises do percentual de umidade nas amostras procedentes da região estudada no Estado da Paraíba, Curimataú Oriental, para as condições proposta de armazenamento com temperatura controlada e armazenamento em condição ambiente. 


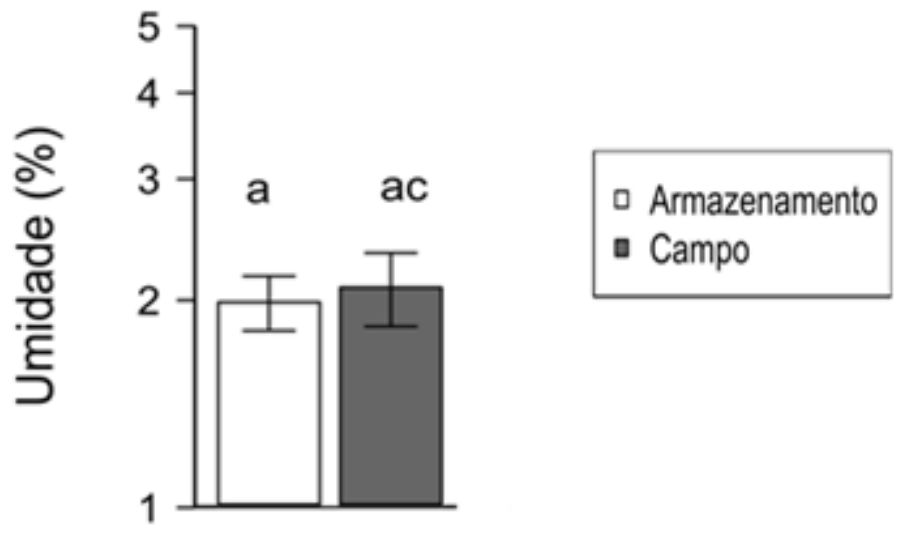

Figura 4. Valores do teor de umidade na Região Curimataú Oriental Paraibano.

Na Figura 4 estão dispostos os resultados obtidos para as análises do percentual de umidade nas amostras procedentes da região estudada no Estado da Paraíba, o Curimataú Oriental para as variáveis de armazenamento com temperatura controlada a $10{ }^{\circ} \mathrm{C}$ e armazenamento sob condição ambiente com temperatura entre $30^{\circ} \mathrm{C}$ e $38^{\circ} \mathrm{C}$.

Quanto aos resultados obtidos para o teor de umidade em virtude das variáveis da vegetação da caatinga em campo e armazenamento em extratos em meio aquoso e etílico, respectivamente, foi possível observar que a própolis verde do Curimataú Oriental que, apresentou média com um valor de 2,015\%. Com média anual para umidade relativa do ar oscilando entre $55 \%$ e $60 \%$, segundo o IBGE (2014).

Para este parâmetro, em virtude da qualidade da própolis e das condições do extrato os níveis de umidade permaneceram com características de qualidade para os extratos da região estudada, a Instrução Normativa MAPA no 3/2001 sugere um máximo de $8 \%$, sendo assim todas as amostras das própolis verde está em conformidade com a lei vigente (MAPA, 2001).

\section{Teor de cera}

Na Figura 5 estão ilustrados os resultados obtidos para as análises do percentual de cera nas amostras procedente da região estudada no Estado da Paraíba, o Curimataú Oriental.

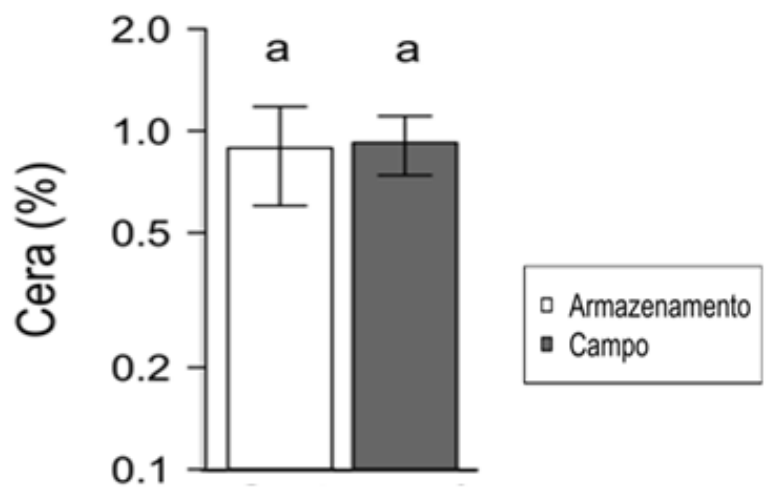

Figura 5. Valores do teor de cera na Região do Curimataú Oriental Paraibano em função da condição de armazenamento com temperatura controlada e condição ambiente. 
Para o parâmetro teor de cera não houve diferença significativa entre as amostras da região sob condição de armazenamento e campo, dos extratos de própolis relacionados ao local onde foram devidamente colhidos.

Os valores encontrados variaram de $0,903 \%$ para o extrato da própolis verde do Curimataú Oriental.

A consistência da própolis está relacionada com o teor de cera em sua composição, sua característica elástica ou quebradiça sugere a quantidade de cera podendo variar entre as amostras de acordo com a região mesmo não apresentando diferença significativa.

De acordo com MAPA (2001) a composição da cera em estudos já realizados com própolis tem relação direta com a vegetação da região de colheita, sua consistência à temperatura ambiente indica a razão entre os teores de resina e cera em sua composição. Estando de acordo com a Legislação Brasileira vigente.

\section{Teor de cinzas}

Na Figura 6 estão ilustrados os resultados obtidos para as análises do percentual de cinzas nas amostras procedente da região estudada no Estado da Paraíba, o Curimataú Oriental no semiárido brasileiro.

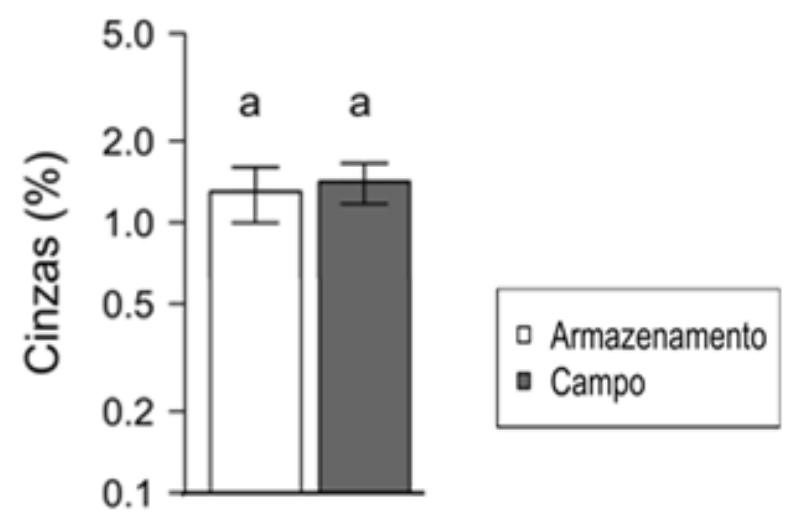

Figura 6. Valores do teor de cinzas na Região Curimataú Oriental Paraibano para a condição de armazenamento e campo.

Para os parâmetros analisados em função da condição de armazenamento controlado com temperatura de $10{ }^{\circ} \mathrm{C}$ e, condição de armazenamento em ambiente/ou de campo, para o teor de cinzas foi de 1,361\%, esse parâmetro é indicativo da quantidade de resíduos inorgânicos não voláteis presentes na própolis, esse aspecto tem um limite máximo de 5\%, estabelecido pela Instrução Normativa MAPA no 3/2001 (MAPA, 2001), que esse extrato atender a lei vigente.

É importante analisar o teor de cinzas proporciona o conhecimento da qualidade da própolis para que não ocorra alteração no produto, quando este é produzido e meio aquoso ou etílico os teores de cinzas não foram diferentes em seu resultados. 


\section{pH}

Na Figura 7 estão ilustrados os valores obtidos para o índice de $\mathrm{pH}$ para a região estudada no Estado da Paraíba, o Curimataú Oriental em função da condição de armazenamento e campo.

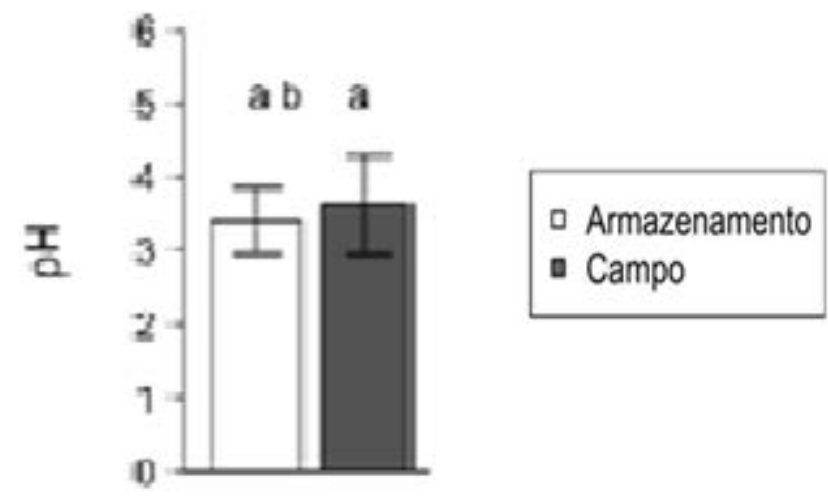

Figura 7. Níveis de pH para as condições de armazenamento e campo na Região do Curimataú Oriental Paraibano.

Os valores para o índice de $\mathrm{pH}$ analisados nas amostras dos extratos da própolis verde apresentaram variação quando submetidos ao armazenamento e na condição de campo, embora este parâmetro não esteja regulamentado ou sugerido pela legislação vigente no Brasil, sua determinação é importante devido à presença de substâncias orgânicas nas amostras de própolis.

Conforme os dados dispostos pode-se verificar que para a condição de armazenamento houve uma diferença significativa comparado aos valores de $\mathrm{pH}$ obtidos para as amostras da mesma região os extratos em condição ambiente, Foi possível observar que houve diferença significativa entre os resultados para os extratos das própolis verde submetidas ao armazenamento.

Kawakita et al. (2015) descreve em seu trabalho que, com relação ao pH, em estudos realizados com extratos de própolis observou que não houve diferença entre as temperaturas utilizadas e tipo de armazenamento ao longo do tempo estudado, de até 12 meses. Por outro lado, destacou que o valor de pH para o extrato de própolis, mantido em temperatura ambiente, apresentou variação significativa a partir do sexto mês. Esses dados sugerem que o $\mathrm{pH}$ pode ser influenciado pela temperatura de armazenamento do extrato de própolis, o autor também salientou que o $\mathrm{pH}$ do extrato alcoólico de própolis tende a ser ligeiramente ácido, variando de 3,0 a 5,7 e, segundo as observações o valor de maior porcentagem de $\mathrm{pH}$ encontra-se em torno de 5,0.

\section{Conclusão}

Foram registrados por amostragem na área de estudo do Curimataú Oriental, 1.669 indivíduos e encontrados 23 espécies, classificadas em 10 famílias botânicas descritas em lista florísticas e vernacular, as cinco mais frequentes, Croton sonderianus, Piptadenia stipulacea, Manihot pseudoglaziovii, Mimosa tenuiflora e Caesalpinia pyramidalis. 
O extrato da própolis verde manteve sua qualidade inalterada para a condição de armazenamento por um período de 12 meses em temperatura constante de $10{ }^{\circ} \mathrm{C}$.

\section{Conflito de interesses}

Os autores declaram não haver conflito de interesses.

\section{Referências}

Alencar, S. M.; Aguiar, C. L.; Paredes-Guzman, J.; Park, Y. K. Composição química de Baccharis dracunculifolia, fonte botânica das própolis dos Estados de São Paulo e Minas Gerais. Ciência Rural, v. 35, p. 909-915, 2005. https://doi.org/10.1590/S010384782005000400025

AOAC - Association of Analytical Chemists. Official methods of analysis. 16. ed. Arlington: AOAC, 1995.

Degáspari, C. H.; Waszczynskyj, N.; Santos, R. J. Atividade antioxidante de extrato de fruto de aroeira (Schinus terebenthifolius Raddi). Visão Acadêmica, v. 5, n. 2, p. 83-89, 2004. https://doi.org/10.5380/acd.v5i2.550

IBGE - Instituto Brasileiro de Geografia e Estatística. Brasil - Paraíba - Panorama. 2014. Disponível em: <https://cidades.ibge.gov.br/brasil/pb/panorama>. Acesso em: 26 nov. 2019.

Kawakita, O.; Souza, E. A.; Uehara, D. U.; Orsi, R. O. Avaliação da vida útil do extrato hidroalcoólico de própolis mantido sob diferentes temperaturas de armazenamento. Atas de Saúde Ambiental, v. 3, n. 1, p. 33-46, 2015.

MAPA - Ministério da Agricultura. Instrução Normativa no 3, de 19 de janeiro de 2001. Disponível em: <http://extranet.agricultura.gov.br/sislegis-consulta/consultar Legislacao.do?operacao=visualizar\&id=1798>. Acesso em: 26 nov. 2019.

Paula, O. M. M.; Mendes, N. S.; Arantes, M. B. S. Quantificação do teor de fenólicos totais de aroeira (Schinus terebinthifolius Raddi) através de duas metodologias distintas. Anais do XXV Congresso Brasileiro de Ciência e Tecnologia de Alimentos, Gramado, p. 24-26, 2016.

Rodal, M. J. N.; Sampaio, E. V. S.; Figueiredo, M. A. (Orgs.). Manual sobre métodos de estudos florístico e fitossociológico: ecossistema caatinga. Brasília: Sociedade Botânica do Brasil, 2013.

Salatino, A.; Teixeira, E. W.; Negri, G. Origin and chemical variation of Brazilian própolis. Evidence-Based Complementary and Alternative Medicine, v. 2, Article ID 759396, 6 p, 2015. https://doi.org/10.1093/ecam/neh060

Teixeira, E. W. Indicadores da origem botânica da própolis: importância e perspectivas. Boletim de Indústria Animal, v. 60, n. 1, p. 83-106, 2003.

Więckiewicz, M.; Miernik M.; Morawie, C. B. Does propolis help to maintain oral health? Evidence-Based Complementary and Alternative Medicine, v. 2013, Article ID 351062, 8 p., 2013. https://doi.org/10.1155/2013/351062 